\title{
Funcionamento Semântico-Enunciativo da Nomeação e da Designação em Apinajé
}

Discoursive-Semantic Functioning

of Naming and Designation in Apinaje Language

Laísa Fernandes Tossin

Universidade de Brasília (UnB)

Resumo. Neste artigo, elaboro uma análise semântico-enunciativa da nomeação e da designação em Apinajé. Discuto o efeito de transparência da linguagem produzido pela estabilização do efeito referencial que gera a ilusão da relação entre linguagem-pensamento-mundo. Apresento dados linguísticos acompanhados de descrições etnográficas e elaboro uma análise dos sufixos $-t i$ e -re, usualmente considerados como sufixos aumentativo (-ti) e diminutivo (-re). Na análise, a hipótese de uma função categorizadora das partículas -ti e -re não se comprova, pois quando comparadas a designação e a nomeação. Portanto, não podemos considerá-las exclusivamente como categoria de filiação dos seres do mundo a uma das metades cerimoniais da sociedade apinaje. Por isso, não significa a revelação de uma estrutura de pensamento projetada sobre o real, mas sim desvela uma estrutura narrativa que se vincula a outras narrativas preexistentes.

Palavras-Chave: Semântica da Enunciação; Designação em Apinajé; Sufixos aumentativo e diminutivo; Onomástica Apinajé; Formações discursivas em Apinajé.

Abstract. This paper presents a discoursive-semantic analysis of naming and designation in Apinaje language. It is the task of this paper to discuss the transparency effect of language produced by the referent's stabilization what generates an illusion link among language-thought-world. Linguistic data are followed by ethnographical descriptions as a manner to enlarge the understanding about the suffixes $(-t i)$ and (-re), usually taken as augmentative and diminutive. The hypothesis about the categorial function of this suffixes does not procced while constrating naming and designation. Therefore, they are not a membership category to link the world too one of the two ceremonial halves of Apinaje society. That is, they do not mean a thought structure projected over the real world, but they reveal a narrative structure connected to other pre-existing narratives.

Keywords: Discourse Semantics; Designation in Apinaje language; Augmentative and diminutive suffixes; Apinaje onomastic; Discursive formation in Apinaje language.

\section{A linguista, seu cesto e os dados naturais}

Eu gosto muito da imagem que Eni Orlandi evoca em seu artigo A natureza e os dados: a linguista com um cesto colhendo dados como se fossem frutas. A prática da pesquisa de campo, como tarefa de "colher" dados linguísticos, é uma herança naturalista que permanece como se a obtenção de dados fosse algo natural, desvinculado das diversas teorias linguísticas. Sob o olhar naturalista, a língua e as coisas da natureza ocupam o mesmo lugar, um lugar de desordem que precisa de uma classificação provida pelo cientista para significar. Os dados, na pesquisa de campo, ainda hoje surgem como produto da natureza e as línguas indígenas são as que mais padecem do viés naturalista. 
Classificar pressupõe análise e analisar é decompor em elementos. Assim como as plantas, a matéria-prima linguística disponível é um manancial para o exercício da classificação naturalista. Os processos de descrição das línguas indígenas são marcados por esta característica de classificação de espécies naturais, como os índios, portanto, são tratadas como um acaso sem história. Sem história de seus processos de construção discursiva dos referentes e sem a história da constituição das ideias linguísticas que serviram, século após século, de modelo teórico para sua descrição. Portanto, a descrição linguística não é desvinculada da teoria, ao contrário, ela "teoriza" a capacidade de referir-se a um ser no mundo.

É importante ressaltar que a necessidade de longa permanência na pesquisa de campo, considerada como premissa fundamental para a cientificidade da tarefa, contradiz justamente a capacidade de produzir um saber por um método, como supõe o método científico e não pela experiência de vida. De modo geral, essas considerações indicam o modelo geral da colonização pela prática científica sob o modo da pesquisa de campo, vivenciada por missionários dedicados a aprender as línguas indígenas para catequizar e por naturalistas com propósitos estatais. (ORLANDI, 1994, p. 55)

\section{O sentido, sua rede de relações discursivas e o tecido ideológico}

Estas colocações abrem caminho para uma reflexão sobre a construção do imaginário científico e do estatuto dessa forma de conhecimento. Um dos efeitos causados pela descrição é o da realidade do pensamento (PÊCHEUX, 2009, p. 164). Valendo-se de seus mecanismos de categorização, a descrição, ao trabalhar a unidade, a variedade e a diferença, produz o efeito de transparência da linguagem provido pela relação entre as palavras e as coisas. Esta impressão de literalidade é produzida pela estabilização do efeito referencial, gerando a ilusão da relação entre linguagempensamento-mundo. O passo seguinte produzido pelo discurso científico é o efeito-verdade.

A Semântica da Enunciação entende que a palavra não significa a coisa, mas é uma forma de o sujeito se relacionar com o real. Esta perspectiva se preocupa com a construção discursiva dos referentes e com os processos de significação. No entanto, não é uma busca por regularidades discursivas formais, pois é no movimento e na dispersão que o discurso encontra sua ordem. A essa ideia de "unidade na dispersão" Pêcheux (2009, p. 160) chamou de formação discursiva. A qual remete a espaços abertos sempre suscetíveis de estruturações e reestruturações que não são dados a priori, mas se constituem como dados à medida que a análise identifica as filiações sócio-históricas presentes no discurso. As diferenças entre formações discursivas distintas são fruto do processo histórico em que as posições dos sujeitos são constituídas. Por isso, derivam de diferenças ideológicas.

Para Bakhtin (1998, p. 41), a palavra é ideológica e serve de trama a todas as relações sociais em todos os domínios. Portanto, a palavra será sempre o indicador mais sensível de todas as transformações sociais. Ao considerar os processos pelos quais as relações entre linguagem, ideologia e poder estabelecem sentidos, desvendam-se os padrões e convenções de sentidos dos quais somos herdeiros, embora, sejamos também criadores ativos de novos sentidos. Para esta tarefa de estabilizar sentidos que remetem a um referente, opera o mecanismo da determinação. É nela que se assenta o efeito de estabilidade do referente, o sentimento do sentido permanente que 
evidencia um mundo semanticamente determinado, um universo logicamente estabilizado. A constituição do sentido por meio da determinação se faz ao reconhecer os predicados descritivos que a estabelecem. Predicados descritivos são a descrição do que as designações (ou nomes) referem no mundo real. Não são as palavras que têm um objeto como referente, são os predicados descritivos que nos dizem que determinada designação significa uma certa coisa no mundo real.

Assumo neste trabalho a posição de que a semântica é uma disciplina linguística que tem o objetivo de compreender o funcionamento das línguas, por isso, não a considero apenas como um componente da gramática das línguas, a trato portanto, como fundamental, já que a língua só interessa porque significa (BENVENISTE, 2005, p. 8; GUIMARÃES, 2018, p. 7). Benveniste (2005, p. 16) ponderou a respeito das impossibilidades de se cumprir um programa de estudos que permita determinar como uma estrutura social se traduz em uma estrutura linguística, pois as correspondências entre uma e outra apresentam muitas discordâncias, tendo em vista que a base comum que rege a língua e a sociedade ainda não foi descoberta. No entanto, Benveniste (2005, p. 11) já amparava todo o trabalho da linguística sobre o discurso ao discutir as implicações da proposta de Z. S. Harris em Methods in structural linguistics de 1951 para a descrição formal dos ambientes de distribuição de fonemas e morfemas em apurada exigência metodológica quase matemática, mas que extirpava as relações de significação.

Sendo o funcionamento dos nomes parte fundamental do modo de significar o mundo, de falar sobre o mundo e de fazer referência às coisas, considero que a designação significa o mundo no momento do enunciado e tomo o enunciado como unidade de análise da semântica. O tempo é, então, decisivo para que o enunciado produza sentido. Podemos dizer, assim, que a história de enunciados produz sentidos. Este acontecimento de enunciação temporalmente marcado e que produz sentido, é produzido em um "espaço de enunciação" delimitado pelas "cenas enunciativas" em que os falantes de uma língua ocupam lugares de enunciação e são agenciados a dizer a partir de seus lugares (GUIMARÃES 2000, 2009, 2017, 2018). Determinar como unidade de análise o enunciado, significa dizer que trato da prática dos falantes de dizerem algo em uma língua num acontecimento específico. O que é dito nesse acontecimento de funcionamento da língua só existe, enquanto tal, nesse acontecimento. Portanto, a enunciação é um acontecimento que produz sentido ao agenciar o falante durante o funcionamento da língua.

\section{As metades, seus astros e os nomes}

Os Apinajé, considerados como um ramo do grupo Timbira, são um dos grupos Jê que habitam o Brasil Central. Suas aldeias circulares com caminhos radiais e uma praça central foram tradicionalmente construídas ao longo do rio Tocantins, mas não à beira d'água. Ocupam o território hoje conhecido como Bico do Papagaio. Como os demais grupos Jê, a organização social dos Apinajé se faz mediante a divisão em metades cerimoniais com funções específicas para cada metade, enfeites e nomes com transmissão avuncular. Procurei abordar as relações que constituem o tecido ideológico que sustenta o processo de significação e de estabelecimento dos sentidos. Para isso, foi preciso assumir como verdade a interpretação dada pelos etnógrafos, assim como tomar as descrições linguísticas já realizadas e reinterpretá-las à luz da Semântica da Enunciação. Estou consciente dos problemas que decorrem deste processo e me responsabilizo por todos eles. 


\subsection{As metades e seus astros}

Odair Giraldin (2000, p. 58-60) descreveu o cosmos compreendido pelos Apinajé como um dualismo complementar e hierárquico. Hierárquico porque os elementos associados à metade relativa ao Leste são considerados melhores que os elementos da metade relativa ao Oeste. Além da divisão Leste/Oeste, o cosmos também se divide em camadas. No nível mais alto da camada exterior está a Lua. Nesta mesma camada, em um nível mais baixo, está o Sol. Na camada intermediária, onde vivem os humanos, as plantas e os animais, a divisão do cosmos se projeta na planta da aldeia que recebe os nomes de "aldeia de cima" para a metade Leste e "aldeia de baixo" para a metade Oeste. O céu é também dividido em dois, a parte que vai do Leste ao zênite é entendido como Kolti, do zênite ao Oeste é Kolre. O planeta Vênus é usado para marcar esta diferença. Ao "nascer" à Oeste, é chamado de "companheira de Lua" (kanhere) e seu brilho é considerado mais fraco. Ao "nascer" à Leste, é chamado de "companheira de Sol" (kanheti) e seu brilho é considerado mais intenso. As metades cerimoniais dos Apinajé organizadas em função do movimento do planeta Vênus no céu chamam-se Kolti e Kolre.

O planeta Vênus realiza uma trajetória de vai-e-vem em relação à Terra, como se rodopiasse em torno do sol. A cada 584 dias, Vênus e Terra se alinham, formando, ao longo de oito anos, um círculo quase completo (99,99\% de precisão). Apenas Júpiter e Vênus desempenham seus movimentos celestiais em relação à Terra com tamanha precisão. Não é apenas o movimento pendular de Vênus que explica a relação entre as metades cerimoniais e os ciclos celestes. Em Nimuendajú (1956, p. 21), ambos os planetas Vênus e Júpiter significam Tamgaága, que é o mesmo nome que recebe o "chefe" da metade Kolti (a metade politicamente mais importante) e que é um nome transmitido de tio a sobrinho. Associando assim, os dois planetas que executam órbitas precisas em relação à Terra (Vênus e Júpiter) à metade Kolti.

Os sufixos -ti e -re presentes em kanheti > kanhere que significam a diferença de intensidade do brilho de Vênus, tradicionalmente, são considerados como aumentativo (-ti) e diminutivo (-re). Quando relacionados à intensidade do brilho do planeta Vênus (kanheti > kanhere), a relação parece conveniente, mas se observarmos o que ocorre com os nomes cosmológicos das metades cerimoniais (Kolti e Kolre) podemos perceber que não é só a relação maior e menor que está em jogo. A diferença de tamanho e intensidade funciona como uma maneira de colocar o mundo dentro das metades, de significá-las como parte do mundo Apinajé. Assim, tanto o movimento do planeta Vênus quanto as plantas, os animais e os seres humanos estão relacionados a um ciclo que envolve as duas metades. O brilho mais intenso e as coisas mais bonitas estão associadas à metade Kolti, por isso recebem o sufixo -ti, e o brilho fraco e as coisas feias estão associadas à metade Kolre, por isso recebem o sufixo -re. As metades cosmológicas conhecidas pelos nomes Kolti - Kolre, segundo Nimuendajú (1956, p. 18), significam Kol-ti ou Kolo-ti, "sapucaia" e Kol-re ou Kolo-re, "castanheira-do-pará". No século XIX, a grafia variava entre Corti e Cority, nome pelo qual eram conhecidos os Apinajé. Outro grupo Kayapó Setentrional também é nomeado com estes mesmos termos: Goro-ti ou Goro-ti-re.

Na mitologia Apinajé, Sol e Lua vieram à terra e criaram as metades Kolti e Kolre. Sol chegou primeiro e são filhos de Mbud-tí (Sol) os Kolti (OLIVEIRA, 1930, p. 81), considerados irmãos mais velhos, aos quais se associa a cor vermelha da pintura com urucum (NIMUENDAJÚ, 1956, p. 19) ou 
a cor preta da pintura com carvão e látex (GIRALDIN, 2000, p. 75), dos quais sempre sairá o "chefe" Apinajé: Tamgaága. A discussão a respeito da cor usada nas pinturas de cada metade é bastante interessante. Dada a distância temporal entre o trabalho de Nimuendajú e o de Giraldin, é possível que as cores tenham sido ressignificadas ou simplesmente trocadas de lado. Giraldin (2000, p. 75) apresentou em sua etnografia uma profunda discussão a respeito das cores presentes nas pinturas corporais de ambas as metades e concluiu que o que as diferencia de fato são os desenhos e não as cores, pois os desenhos são, em geral, pintados de preto sobre um fundo vermelho. Portanto, as pinturas horizontais são Kolre e as verticais Kolti.

Tudo o que está associado à metade Kolti é mais bonito. A árvore Kolti, ou como a conhecemos, "sapucaia", é de grande porte, chegando a até $30 \mathrm{~m}$ de altura, com copa densa de folhas jovens lindamente coloridas de lilás arroxeado que se misturam com as flores arroxeadas durante o momento da floração que acontece em um período curto, de setembro a outubro, e atrai inúmeras abelhas para a polinização. Os frutos são arredondados, com casca rígida e atingem a maturação entre agosto e setembro, ou seja, os frutos levam 10 meses aproximadamente para amadurecer, formando um ciclo único durante um ano solar. Os morcegos são os principais responsáveis pelo processo de disseminação de sementes.

Lua chegou depois, não encontrou o lugar combinado para que os dois irmãos se encontrassem e se atrasou. São filhos de Mbuduvrí-re (Lua) os Kolre, considerados irmãos mais novos, aos quais se associa a cor preta da pintura de carvão e látex vegetal ou, segundo Giraldin (2000, p. 75), a cor vermelha da pintura com urucum. Tudo que está associado a ele é feio. A árvore Kolre, ou "castanheira", é de grande porte, chegando a até $50 \mathrm{~m}$ de altura, com copa densa e floração de cor amarela que acontece nos meses de setembro a fevereiro, com pico de outubro a dezembro. A floração não é por si só atraente aos polinizadores, sendo necessária a presença de orquídeas perfumadas para atrair as abelhas macho que impregnadas com o odor das orquídeas atraem as fêmeas, maiores e fortes o suficiente para abrirem as pétalas da flor da castanheira e assim polinizá-las com sua língua tão comprida que consegue passar pela espiral da flor. Esta abelha é a mangavá ou mamangava, também chamada de zangão. Os frutos arredondados e com casca rígida levam de 12 a 15 meses para amadurecer, o que acontece em fevereiro, formando um ciclo que ultrapassa o ano solar. As cotias são as principais disseminadoras das sementes da castanheira.

Se pensarmos em uma associação direta entre maior e menor, podemos perceber que a castanheira pode ser mais alta que a sapucaia. Em relação a noite e dia, os morcegos que disseminam as sementes da sapucaia são animais noturnos e as cotias que disseminam as sementes da castanheira são animais diurnos. Então, uma relação direta entre dia e noite, maior e menor não é a melhor maneira de entendermos o modo de construção da significação dos nomes atribuídos às metades cerimoniais em Apinajé. Se pensarmos nas peculiaridades semelhantes, podemos perceber que ambas produzem frutos oleaginosos envoltos em espessas cascas arredondadas dos quais se extraem perfumados óleos. Ambas florescem exuberantemente em outubro e têm abelhas como polinizadoras. A deslumbrante inflorescência arroxeada da sapucaia permite que sua polinização aconteça sem maiores problemas. Já a imponente castanheira tem uma difícil inflorescência amarelada incapaz de atrair sua única polinizadora, sendo necessária a presença de orquídeas perfumadas para atraí-las. Se pensarmos nos sistemas reprodutivos de cada uma delas, a 
vulnerabilidade da robusta castanheira se opõe à fertilidade da exuberante sapucaia. A ideia de oposição só serve aqui como meramente ilustrativa da explicação, porque se a deslocarmos para a relação entre os irmãos demiurgos e posteriormente às relações entre nomeados e nomeadores, ela não opera como oposição. Há uma relação de ajuda mútua, de duplicidade cúmplice. Talvez o equívoco seja tratá-las como metades. Uma metade é sempre incompleta e não significa a duplicidade cúmplice expressa por Kolti e Kolre.

Se consideramos kol- ou kolo como uma raiz lexical que designa "árvore", teríamos para ambas as árvores um mesmo predicado descritivo que poderia ser entendido como um categorizador para árvore, como um termo genérico e abrangente. Outro entendimento aponta para a construção de um processo histórico descritivo que soma predicados descritivos, não associando-os diretamente à coisa nem à morfologia, mas integrando uma narrativa que se estende temporalmente e que constitui o discurso, formando assim um texto significativo no qual as relações de sentido operam e se reproduzem nos dizeres de seus falantes. De acordo com este entendimento, kol- ou kolo não significam árvore em sentido genérico, representativo ou simbólico, kol- ou kolo significam a relação entre estas duas árvores específicas, com todas as suas peculiaridades implicadas, e a vida cosmológica apinajé. Os sentidos que kolti e kolre circulam são estritamente discursivos e só significam quando operam a rede de relações discursivas que compõem os textos narrados pelos falantes da língua.

Traçar estas relações nos permite também vislumbrar que a raiz kolo presente em kolti e kolre não aponta para uma relação direta entre palavra e coisa. Uma mesma raiz lexical serve para designar duas árvores diferentes. Sendo -ti e -re sufixos relativos à cada uma das metades cerimoniais, kolo não significa nenhuma das árvores enquanto objeto material, significa sim a expressão das relações apinajé em suas várias camadas de sentido. Também podemos vislumbrar que a relação direta entre morfologia e objeto material não opera, visto que os sufixos -ti e -re estão presentes em diversas outras palavras não relacionadas a árvores. Os sufixos -ti e -re estão presentes também em nomes de palmeiras e de animais como por exemplo:

kamêrti significando "bacaba"

kamêre significando "juçara"

pet kak ti significando "tamanduá bandeira"

pet kak re significando "tamanduá-mirim"

Em outros exemplos, há a presença de -ti ou de -re marcando a relação de par hierárquico existente entre dois seres. Por exemplo:
prïn significando "pequi"
prïn re significando "oiti"
pet kek significando "preguiça"
pet kek ti significando "guariba"
rop kró significando "onça-pintada"
rop kró re significando "jaguatirica"
gwra significando "buriti"
gwrare significando "buritirana" 
Sempre as relações expressas pelo sufixo -ti significam frutos mais saborosos ou mais doces, animais maiores ou mais ágeis. Enfim, há uma compreensão geral de que -ti significa algo superior na percepção dos Apinajé. De certa forma, os sufixos -ti e -re funcionam como categorias classificatórias do pensamento apinajé. No entanto, seria precipitado afirmar que esta relação entre léxico e lógica classificatória funcionaria como um sistema bem-definido no qual as categorias possuem objetos que não se misturam. Ao estudarmos o funcionamento discursivo dos nomes pessoais, poderemos perceber que estes limites não são tão claros assim.

Nas diversas camadas de sentido expressas por Kolti e Kolre, tais como: sapucaia e castanheira; maior e menor; mais intenso e menos intenso; irmão mais velho e irmão mais novo; há também as relações com o sol e a lua. Morfologicamente, este par é semelhante a Kolti e Kolre, onde duas árvores distintas recebem apenas os sufixos _ti e _re que determinam seu porte e marcam a relação com uma das metades cerimoniais, como marca morfológica capaz de apontar alguma diferença no referente. Sol e Lua, 'bitti e 'bitwrëre (OLIVEIRA, 2005, p. 372), também carregam os sufixos_ti e_re que determinam seu porte e marcam a relação com uma das metades cerimoniais. Assim:

"bitti; onde "bit significa "astro" e -ti é o sufixo que o relaciona à Kolti e determina seu porte: grande, ou seja, bitti significa "sol";

"bitwrëre; onde "bit significa "astro"; wrë significa "distante" e -re é o sufixo que o relaciona à Kolre e determina seu porte: pequeno, ou seja, "bitwrëre significa "lua".

Nesta interpretação das determinações morfológicas, a lua está mais afastada, menos intensa, menor. Tanto sol quanto lua, assim como castanheira e sapucaia, não têm em suas raízes lexicais nenhuma identificação que possa diferenciá-los um do outro. São os sufixos -ti e -re que marcam esta diferença. Apresento o funcionamento dos sufixos -ti e -re na designação do ciclo lunar para verificarmos que as relações apontadas ultrapassam os limites significativos de maior e menor. Vejamos:

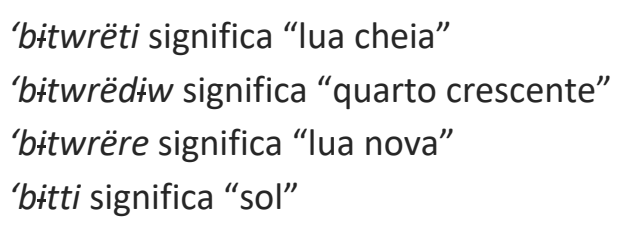

Com o quadro completo das variações de 'bit-, podemos vislumbrar a associação de 'bitti e 'bitwrëre às metades cerimoniais. Assim, 'bitti, com seu brilho intenso, está associado à metade Kolti e "bitwrëre, com a ausência de luz, à metade Kolre. No entanto, "bitwrëti "lua cheia" está associado à metade Kolti. Desta forma, teríamos para a metade Kolti, "bitti "sol" e "bitwrëti "lua cheia" e toda a visibilidade que a luz pode fornecer. Para a metade Kolre, "bitwrëre "lua nova" e a cegueira proporcionada pela escuridão.

Em bitwrëdiw se aloca a expressão de movimento em direção de atingir a plenitude de sua grandeza ou, em outros termos, de crescer. Tendo em vista que -diw designa também aquele que está em fase de crescimento. Como Da Matta (1976, p. 123) esclareceu a respeito das formas de tratamento entre nomeado e nomeador: 
id-krã-tum "nomeador"; onde id-krã significa "minha cabeça" e tum "velha"

$i d-k r \tilde{a}$-diw "nomeado"; onde id-krã significa "minha cabeça" e diłw "nova", no sentido de jovem, ainda criança.

Sendo o nomeado uma criança, a diferença de tamanho é também uma diferença hierárquica, mas significa que a criança vai crescer e se tornar adulto como seu nomeador e terá as mesmas funções e obrigações cerimoniais nas festas. Aqui também é possível entender que a lua em fase crescente (ou minguante) é, ao mesmo tempo, luz e escuridão; é simultaneamente Kolti e Kolre. Exatamente como Mbud-tí (Sol) e Mbuduvrí-re (Lua) recomendaram a seus filhos que fizessem, que se casassem uns com os outros e tivessem filhos, enfim, se misturassem. Kolti e Kolre não são as únicas metades que organizam a vida social apinajé. Odair Giraldin (2000, p. 74-75) descreveu outros pares de metades conhecidos como: Waxmë e Katàm; Hipôknhõxwynh e Ixkrénhõxwynh. As metades Waxmë (Kolti) e Katàm (Kolre) definem os times das corridas de toras e suas respectivas pinturas que utilizam ambas as cores, vermelho e preto, em sua confecção. Hipôknhõxwynh (Kolti) e Ixkrénhõxwynh (Kolre) se referem aos comportamentos associados a cada uma das metades. Hipôknhõxwynh (Kolti) apresenta um comportamento extrovertido e brincalhão de pessoas inconstantes e mentirosas tido como o comportamento ideal para o modelo social apinaje. Ixkrénhõxwynh (Kolre) apresenta um comportamento mais tímido e sério de pessoas que falam a verdade e que são sossegadas e vagarosas. Cada indivíduo pertence a várias metades diferentes: Kolti; Waxmë; Hipôknhõxwynh. Este pertencimento plural, às vezes, se estende ao pertencimento a ambas as metades (Kolti e Kolre) simultaneamente. Como descreveu Giraldin (2000, p. 112-115) a respeito das associações entre amigos formais e nomeados que trazem implicações para o pertencimento do nomeado a uma ou outra metade, ou a ambas as metades simultaneamente. Nestes casos, há a possibilidade de o nomeado "escolher" se sua índole é mais Hipôknhõxwynh ou Ixkrénhõxwynh e apresentar-se como tal. Há uma superposição de camadas de pertencimento e de significação que transforma nosso desejo de buscar um sistema classificador que reflita a lógica do pensamento apinajé em uma meta inatingível.

\subsection{Os nomes}

Em geral, os rituais de nomeação têm início ao final da tarde, quase ao pôr do sol e seguem noite adentro. Castelneau, citado por Nimuendajú (1956, p. 21), mencionou a posição da lua no zênite durante o momento da transmissão dos nomes em um ritual de nomeação, mas não estabeleceu uma relação entre as duas coisas. Giraldin (2000, p. 123) descreveu o período em que aparecem os primeiros raios de sol como sendo o momento da transmissão de nomes.

Para que a nomeação ocorra, os pais escolhem entre a parentela consanguínea ou classificatória da criança alguém que transmita seus nomes à criança, inserindo-a assim na vida social da aldeia. O nomeador não precisa ser necessariamente parente da criança, nem mesmo precisam ser integrantes da mesma metade. O nomeador precisa confeccionar os adornos cerimoniais apropriados que junto com os nomes determinam o lugar social da criança e as responsabilidades que ela terá. Os nomes sempre estão associados a kolti ou kolre e às atividades cerimoniais desempenhadas por cada metade. Há "nomes grandes" e "nomes pequenos" em ambas 
as metades. Aos "nomes grandes" estão atribuídas atividades relacionadas com a produção de comida e a organização do trabalho para que as festas aconteçam. Assim, o nome não é exatamente uma forma individualizadora de reconhecimento da pessoa, mas insere um corpo a uma dinâmica social e lhe dá um significado, pois haverá sempre a versão adulta e a versão jovem de um mesmo nome, garantindo assim a reprodução social e ritual.

Nimuendajú (1956, p. 22-25) e Da Matta (1976, p. 109) descreveram festas em que duplas de nomes trabalham juntas para que a festa aconteça, sendo as atribuições associadas a cada nome descritas por eles tais como as reproduzo aqui.

Quadro 1

\begin{tabular}{|l|l|l|}
\hline Kolti & Kolre & Papel cerimonial \\
\hline Tegatóro & Rãraké & Iniciam as corridas de tora \\
\hline Amdyi* & Koko* & Moças que participam da iniciação dos peb (moços) \\
\hline Konduká & Konduprin & Tem direito de exigir comidas especiais para suas festas. \\
\hline Pánti* & $\begin{array}{l}\text { Organiza uma festa para a qual se faz uma roça de milho. } \\
\text { Quando maduro, convida-se os moradores de outras } \\
\text { aldeias para a colheita. }\end{array}$ \\
\hline & Ireti* & $\begin{array}{l}\text { Cantadora das festas em que os guerreiros incendiavam } \\
\text { o campo para caçar. }\end{array}$ \\
\hline$*$ Nomes femininos & Amdyág & Cantadora na festa Ro'ród \\
\hline
\end{tabular}

No entanto, Odair Giraldin (2000, p. 115) não conseguiu verificar em seu convívio com os Apinajé a ocorrência destes nomes com estas atribuições e semelhantes festas. Mas pôde verificar que o nome Ngrére possui a atribuição de ouvir, aprender e reproduzir os cantos de lamentação de pessoas, plantas, animais e objetos que estejam sofrendo. Também pôde verificar que o nome Rãraké não foi reconhecido por seu informante e que Konduká e Konduprin são duas formas diferentes de um mesmo nome. Ainda assim, a ideia de que os "nomes grandes" estão associados às metades e que filiam seus portadores a uma destas metades persistiu na descrição de Giraldin.

Segundo Giraldin (2000, p. 111), a maneira de filiar-se a outras metades como Hipôknhõxwynh ou Ixkrénhõxwynh se dá por meio do arranjador do nome que não é obrigatoriamente filiado à mesma metade que o nomeado. Portanto, um nomeado pode, no momento de sua nomeação, filiar-se à metade Kolti e à metade Ixkrénhõxwynhi, por parte de seu arranjador de nome.

Quanto ao funcionamento semântico-enunciativo, dar nome é identificar um indivíduo biológico para a sociedade (GUIMARÃES, 2018, p. 191), portanto a nomeação é de um lugar social que não é o da paternidade ou maternidade, mas parte do agenciamento de um enunciador que já está nomeado com o mesmo nome com o qual nomeará o novo ser. Ao mesmo tempo em que a história da enunciação de transmissão deste nome dá ao nome um lugar social, o lugar de dizer a transmissão do nome é um lugar individual. O nomeador, então, apresenta-se como um enunciadorindividual em uma cena enunciativa determinada e estabelece a conexão específica entre nome e nomeado. Assim, a escolha do nome não é exatamente uma escolha. 0 nome está vinculado a uma história de enunciações, que é a repetição da nomeação, e opera uma "tradição" onomástica que recorta um significado memorável transmitido junto ao nome. 
Nimuendajú (1956, p. 21) nos contou como foi sua nomeação, quando recebeu de Tamgaáti, filho de Pembre, seu nome. Depois de pintado e adornado, assistiu a doze pares enfileirados frente a frente que dançaram ao som de um cantador e seu maracá. Sentados em uma esteira na casa de Pembre, estavam Nimuendajú e um rapaz que também tinha o nome de Tamgaá-ti. Em frente aos dois, Tamgaá-ti, filho de Pembre, pronunciou devagar e solenemente os cinco nomes de Tamgaága: "Tamgaá-ti! Tamgaá-glú'ti! Tamgaága-rerég-ti! Tamgaága-rãtém-ti! Tamgaága-rái-ti!" Esta cena enunciativa produz uma vinculação específica entre um nome e uma pessoa e este vínculo será um funcionamento desse nome. Embora o nome tenha o funcionamento de um nome próprio e vincule uma pessoa a um nome, de fato, vincula várias pessoas a um grupo de nomes. Mesmo que este nome esteja vinculado a mais de uma pessoa, neste momento, cria-se o elo entre esta determinada pessoa e os nomes Tamgaága, o que o torna um memorável decisivo para o funcionamento deste nome enquanto nome próprio de pessoa. Tamgaága é o nome de Vênus e de Júpiter. Baseado no movimento pendular de Vênus, a metade Kolti significa a metade politicamente mais importante e dela emerge o líder político e cerimonial do grupo social: Tamgaága. A origem do nome evoca a origem do tempo, da criação do mundo enquanto fruto da criação estético-verbal dos Apinajé.

Embora o funcionamento do nome seja o tema estudado aqui, a relação mais importante neste acontecimento de nomeação é a relação social formal que vai se estabelecer entre o arranjador do nome e o nomeado (GIRALDIN, 2000, p. 112). Esta relação reproduz, na escala humana, a relação de companheirismo entre os demiurgos Sol e Lua quando viveram na Terra. A relação formal rege os movimentos sociais da vida cotidiana com seus conflitos, problemas e soluções. Os procedimentos do luto, os arranjos de casamento, pagamento de serviços cerimoniais são as várias atividades às quais os amigos formais recorrem uns aos outros para a execução. Os nomes também servem ao propósito de gerar uma rede de solidariedade, em especial, para o desempenho de cerimônias que exigem muita produção de comida, urucum para as pinturas corporais e distribuição de presentes para os cantadores, mas as relações proporcionadas entre o grupo de amigos formais ampliam as possibilidades de ajuda, mesmo para idosos e para aqueles que não têm uma parentela consanguínea grande.

\section{Breves considerações finais}

O funcionamento dos nomes em Apinajé nos revelou duas importantes coisas. A primeira, que a relação sistemática esperada como função categorizadora das partículas -ti e -re não se comprovou quando comparadas a designação e a nomeação, portanto, não podemos considerá-las exclusivamente como categoria de filiação dos seres do mundo a uma das metades cerimoniais da sociedade apinajé. Há uma estratégia discursiva que vincula o mundo a um lugar narrativo que o significa e o põe em funcionamento. Por isso, esta vinculação não significa a revelação de uma estrutura de pensamento projetada sobre o real, mas sim desvela uma estrutura narrativa que se vincula a outras narrativas compartilhadas com outros grupos sociais, como no caso das histórias dos dois irmãos demiurgos Sol e Lua, que são muito correntes entre diversos grupos sociais do continente. A vinculação a outras narrativas traz a importante consideração de que estas narrativas não "brotaram" do pensamento apinajé, mas sim foram ressignificadas e usadas pelo grupo como 
modo discursivo de filiar-se a uma tradição narrativa ampla e extensa ao mesmo tempo em que funciona como demarcadora de características próprias do grupo, portanto, o faz diferente dos demais, ao acrescentar ou suprimir detalhes em cada uma das histórias.

A segunda, parte da compreensão de que uma estrutura narrativa não é uma projeção do pensamento sobre o real, mas sim uma estratégia discursiva para criar relações significativas com o mundo. Desta maneira, as relações linguísticas que associam o sentido à morfologia não se mostram produtivas, pois a morfologia por si só não cria as distinções necessárias para nomear o mundo com uma etiqueta diferente para cada ser. Assim, as dispersões linguísticas reconstruídas exclusivamente por meio de estudos morfofonológicos deixam escapar os melindres elaborados pelas estratégias narrativas que dão sentido aos aspectos formais da designação do mundo e revelam profundas relações entre grupos sociais considerados linguisticamente apartados. Esta perspectiva pode nos demonstrar vinculações narrativas entre grupos sociais bastante extensas, do ponto de vista geográfico, e, assim, nos apontar outros caminhos linguísticos de conexão comunicacional existentes no continente antes da chegada dos europeus.

\section{Referências}

BAKHTIN, M. Questões de Literatura e de Estética. A Teoria do Romance. 4. ed. Unesp/Hucitec: São Paulo, 1998.

BENVENISTE, E. Problemas de Linguística Geral I. 5. ed. Pontes: Campinas/SP, 2005.

DAMATTA, R. Um mundo dividido. A estrutura social apinayé. 10. ed. Vozes: Petrópolis/RJ, 1976. Coleção Antropologia.

GIRALDIN, O. Axpên piràk. História, cosmologia, onomástica e amizade formal apinajé. 2000. Tese (Doutorado em Antropologia), Instituto de Filosofia e Ciências Humanas, Universidade Estadual de Campinas, Campinas/SP, 2000.

GUIMARÃES, E. "Terra de Vera Cruz, Brasil”. Revista de Cultura Vozes. São Paulo, 1992.

GUIMARÃES, E. "Linguagem e Mito - uma concepção de sentido e de texto." Línguas e Instrumentos Linguísticos, vol. 2. Campinas, 1998.

GUIMARÃES, E. “Um mapa e suas ruas". In: ORLANDI, E. (Org.). Cidade Atravessada. Campinas/SP: Pontes, 1999.

GUIMARÃES, E. Semântica do Acontecimento. Campinas/SP: Pontes, 2002.

GUIMARÃES, E. Domínio Semântico de Determinação. Palavra: Forma e Sentido. Campinas: Pontes/RG, 2007.

GUIMARÃES, E. Enumeração: funcionamento enunciativo e sentido. Cadernos de Estudos Linguísticos, vol. 51, n. 1, 2009.

GUIMARÃES, E. Em torno do nome próprio de cidade. Sobre a produção de uma origem. Cadernos de Estudos Linguísticos, vol. 53, n. 2, 2011. 
GUIMARÃES, E. Aposto e nome próprio. Entremeios, vol. 5. Pouso Alegre: PPGCL/Univás, 2012.

GUIMARÃES, E. Semântica, Enunciação e sentido. Campinas/SP: Pontes, 2018.

NIMUENDAJÚ, C. Os Apinajé. Boletim do Museu Paraense Emilio Goeldi, T. XII, 1956.

PÊCHEUX, M. Semântica e Discurso. Uma crítica à afirmação do óbvio. 4. ed. Editora Unicamp: Campinas, 2009.

PESCE, C. Oleaginosas da Amazônia. 2 ed. Belém: Museu Paraense Emílio Goeldi. Núcleo de Estudos Agrários e Desenvolvimento Atual Rural, 2009.

OLIVEIRA, C. The Language of the Apinajé People of Central Brazil. 2005. Tese. Departamento de Linguística da Universidade de Oregon, Oregon, 2005.

OLIVEIRA, C. E. Os Apinagé do Alto Tocantins. Boletim do Museu Nacional, vol. VI, n. 2, p. 61-110, jun. 1930.

ORLANDI, E. P. A natureza e os dados. (A constituição histórica de um modelo de pesquisa de campo). Cadernos de Estudos Linguísticos, n. 27, p. 45-57, jul./dez. 1994.

TOSSIN, L. Intransitividade cindida em Apinajé. 2009. Dissertação (Mestrado em Linguística), Programa de Pós-graduação em Linguística, Universidade de Brasília, Brasília, 2009. 116 p.

TOSSIN, L. Uma questão de essência: classificadores para o corpo humano em Apinayé. Revista Moara, n. 43, vol. 2, p. 129-140, jul./ dez. 2015. 